\title{
Differential expression of Notch1 intracellular domain and p21 proteins, and their clinical significance in gastric cancer
}

\author{
DING-HAI LUO ${ }^{1,2}$, QIN ZHOU $^{1}$, SUN-KUAN HU ${ }^{1}$ YI-QUN XIA ${ }^{1}$ CHAO-CHAO XU $^{1}$, \\ TIE-SU LIN ${ }^{1}$ YU-TING PAN ${ }^{1}$ JIAN-SHENG WU ${ }^{1}$ and RONG JIN ${ }^{1,3}$ \\ ${ }^{1}$ Department of Digestive Diseases, The First Affiliated Hospital of Wenzhou Medical College, Wenzhou, Zhejiang 325000; \\ ${ }^{2}$ Department of Gastroenterology, Taizhou Hospital, Linhai, Zhejiang 317000; ${ }^{3}$ Department of Epidemiology, \\ The First Affiliated Hospital of Wenzhou Medical College, Wenzhou, Zhejiang 325000, P.R. China
}

Received March 15, 2013; Accepted October 1, 2013

DOI: $10.3892 / \mathrm{ol} .2013 .1751$

\begin{abstract}
Changes in the expression of the Notch1 intracellular domain (NICD) and p21 proteins have been shown to be closely associated with the development and progression of a number of cancers. The present study aimed to investigate the expression levels of the two proteins in gastric carcinoma and precancerous lesions, and to determine the clinical significance of this. A total of 109 gastric cancer, 57 precancerous gastric lesion, 50 chronic superficial gastritis and 17 normal gastric mucosa patients were recruited for immunohistochemical staining of NICD and p21 protein expression. The protein expression levels in the gastric cancer patient samples were associated with the clinicopathological and survival data. NICD protein levels were upregulated gradually from normal gastric mucosae through chronic superficial gastritis and precancerous gastric lesions to gastric cancer tissues $(\mathrm{P}<0.01)$, whereas p21 protein levels were downregulated accordingly $(\mathrm{P}<0.01)$. Increased NICD and a loss of p21 expression were closely associated with tumor dedifferentiation, depth of tumor invasion, lymph node metastasis, surface morphology and Lauren classification in gastric cancer. Thus, NICD expression was inversely associated with p21 expression. In addition, the overall survival rate was greater in $\mathrm{NICD}^{-}$and $\mathrm{P}^{2} 1^{+}$patients than in $\mathrm{NICD}^{+}$and $\mathrm{P}^{2} 1^{-}$patients, respectively $(\mathrm{P}<0.05)$. The COX regression multivariate analysis revealed that $\mathrm{NICD}^{+}$, p21 $1^{-}$, depth of tumor invasion and lymph node metastasis were all independent prognostic factors for patients with gastric cancer. NICD and p21 proteins are differentially expressed in gastric cancer and the aberrant expression of these proteins
\end{abstract}

Correspondence to: Professor Rong Jin, Department of Epidemiology, The First Affiliated Hospital of Wenzhou Medical College, 96 Fu Xue Road, Wenzhou, Zhejiang 325000, P.R. China E-mail: jinrongjrjr@163.com

Key words: Notch1 intracellular doman, p21, gastric cancer, prognosis, biomarkers is associated with an advanced tumor stage, tumor metastasis and overall patient survival. Future studies are required to further evaluate the two proteins as novel prognostic markers for patients with gastric cancer.

\section{Introduction}

Gastric cancer is a significant health problem worldwide, particularly in developing countries, and it accounts for approximately one million new cancer cases per year. In 2008, up to $72 \%$ of new cases occurred in developing countries, resulting in 738,000 cancer-related mortalities (1). Furthermore, China alone accounts for $42 \%$ of the worldwide gastric cancer cases (2). To date, a number of improvements have been made for early detection and surgical approaches in the treatment of early gastric cancer. The overall five-year survival rate is as high as $95-100 \%$ for early cancer patients. However, the majority of patients are diagnosed at an advanced stage of disease, which makes a cure by surgery impossible, leading to a poor overall five-year survival rate. If patients are able to undergo a complete radical surgery, the overall five-year survival rate may reach $30-40 \%$. Therefore, an early diagnosis of gastric cancer and surgery are essential for patients to achieve an improved prognosis. Thus, the development and identification of biomarkers for early detection and prognosis prediction are urgently required.

The Notch1 signaling pathway, an evolutionarily conserved cell interaction mechanism, is involved in embryo development and normal cell proliferation, differentiation, survival and apoptosis, including the induction of radial glia and astrocyte differentiation. However, alterations of this gene pathway contribute to the development of various human cancers and their progression $(3,4)$. Normally, Notch1, a transmembrane protein, is activated by ligand-induced proteolysis, leading to the release of the Notch1 intracellular domain (NICD) from the cytolemma and in turn translocation into the nuclei of cells for controlling the expression of certain genes, including Hes-1 and Hes-5. These downstream target genes are typically regulated through an interaction between NICD and the DNA-binding transcription factor protein, CSL, which maintains normal homeostasis in the human body (5). However, 
dysregulation of Notch1 or the expression of its functional domain, NICD, may be involved in tumorigenesis. A previous study has shown that abnormal Notchl signaling contributes to the development and occurrence of gastric cancer (6).

Furthermore, p21/WAF1 protein, also known as cyclin-dependent kinase (CKD) inhibitor 1, is able to bind to and inhibit the activity of cyclin-CDK2 complexes, thus regulating the G1 phase progression of the cell cycle. Normally, p21 expression is tightly controlled by the tumor suppressor protein, p53, to mediate p53-dependent G1 arrest of the cell cycle in response to a variety of stress stimuli. A number of studies have shown that the activation of Notch1 signaling promotes $\mathrm{p} 21$ expression in certain types of tumor cells, but inhibits p21 expression in other types $(7,15)$. Specifically, a previous study has shown that Notch signaling induced cell cycle arrest in small cell lung cancer cells (7). Another study has revealed that activated Notch1 interacted with p53 to inhibit its phosphorylation and transactivation (12). In addition, Notch1 has been shown to regulate the Akt signaling pathway and the expression of the cell cycle regulatory proteins cyclin D1, CDK2 and p21 in T-cell acute lymphoblastic leukemia cell lines (15). Therefore, the association between NICD and p21 proteins and the expression of these proteins in gastric cancer development and progression requires further investigation. Thus, in the present study, an immunohistochemical analysis of the two proteins in gastric tissues with varying degrees of histological development was performed to assess their association with gastric cancer.

\section{Patients and methods}

Tissue specimens. In the present study, 109 surgically resected tissue specimens were retrospectively retrieved from gastric cancer patients who underwent surgery between 2007 and 2009 at The First Affiliated Hospital of Wenzhou Medical College, Wenzhou, China. The patient group comprised 83 males and 26 females, with a mean age of 60.5 years old [standard deviation (SD), \pm 11.3$]$. All patients were histopathologically diagnosed with well-differentiated adenocarcinoma $(\mathrm{n}=5)$, moderately differentiated adenocarcinoma $(n=42)$ or poorly differentiated adenocarcinoma $(n=62)$ of the stomach. The patients were diagnosed according to the tumor-node-metastasis staging system by the 1997 International Union Against Cancer, with stage I $(n=15,13.8 \%)$, stage II $(n=18,16.5 \%)$, stage III $(n=46$, $42.2 \%)$ and stage IV $(\mathrm{n}=30,27.5 \%)$ tumors. No patients were administered any neoadjuvant therapy prior to surgery. In addition, biopsy specimens were obtained from 17 subjects with normal gastric mucosa (who were healthy persons or presented with some symptoms but had histologically normal gastric mucosae), 50 patients with chronic superficial gastritis and 57 patients with precancerous gastric lesions (four cases with a gastric ulcer, two cases with a gastric polyp and 51 cases with chronic atrophic gastritis) through endoscopy. In the normal gastric mucosa group, there were nine males and eight females (mean age $\pm \mathrm{SD}, 42.2 \pm 9.8$ years). In the chronic superficial gastritis group, there were 27 males and 23 females (mean age $\pm \mathrm{SD}, 40.4 \pm 10.4$ years) and in the precancerous gastric lesion group (nine chronic atrophic gastritis, 26 atrophic gastritis with intestinal metaplasia, three chronic superficial gastritis with focal areas of atrophic intestinal metaplasia and three atypical hyperplasia patients), there were 35 males and 22 females (mean age \pm SD, $47.2 \pm 12.4$ years). Approval for this study was obtained from the Ethics Review Committee of The First Affiliated Hospital of Wenzhou Medical College. Written informed consent was obtained from each patient. All tissue specimens were fixed in $10 \%$ formalin and embedded in paraffin. The patients with gastric cancer were followed up at our outpatient clinic until they succumbed to the disease. The last follow-up appointment was on April 1, 2011.

Immunohistochemistry. For immunohistochemical staining, the paraffin blocks of each patient were retrieved from the Pathology Department and cut into 3- $\mu \mathrm{m}$ thick sections onto $1 \%$ polylysine-coated glass slides. The first section of each block was stained with hematoxylin and eosin to reconfirm the pathological diagnosis. The sections were then stained immunohistochemically using a standard biotin-streptavidin-peroxidase method according to a previous study (16). The primary rabbit anti-human NICD antibody was purchased from Merck-Millipore (Darmstadt, Germany) and diluted at 1:100. The mouse anti-human p21 antibody was obtained from Santa Cruz Biotechnology, Inc. (Santa Cruz, CA, USA) and diluted at 1:50. The secondary antibody and the universal immunohistochemical staining kit (PV6001 and PV9003, respectively) were purchased from Zhongshan Goldenbridge Biotechnology Company (Zhongshan, China).

Review and scoring of the immunostained tissue sections. The immunostained tissue sections were independently reviewed and scored under a microscope by two pathologists. A brown color or light brown particles in the cytoplasm and/or the nucleus of the cells was considered as positive staining. A total of 10 fields were randomly selected at low magnification (x40) and 100 epithelial cells from each field were counted. The fields were scored as $0(<1 \%$ of the cells stained), one (1-19\% staining), two (20-40\% staining) or three ( $>40 \%$ staining), according to a previous study (16). p21 protein was reviewed using the same procedure as for NICD, and scored as $0(<1 \%$ of the cells stained), one (1-24\% staining), two (25-75\% staining) or three ( $>75 \%$ staining), as described previously (16).

Statistical analyses. All data were analyzed using SPSS 16.0 statistical software (SPSS, Inc., Chicago, IL, USA). The comparison between the groups was analyzed using the $\chi^{2}$ test. The correlation of variables was analyzed using the Spearman's rank correlation test. The survival rates were calculated using the Kaplan-Meier method and compared by the log-rank test. The Cox proportional hazards regression model was used to measure the independent contribution of each variable to the overall survival. $\mathrm{P}<0.05$ was considered to indicate a statistically significant difference.

\section{Results}

Differential expression of NICD and p21 proteins in gastric cancer, precancerous gastric lesions and normal gastric tissues. In the present study, NICD expression was first detected in the gastric tissue specimens. The NICD protein was observed to be mainly expressed in the nuclei of epithelial cells and occasionally in the cytoplasm. The NICD protein was 
A

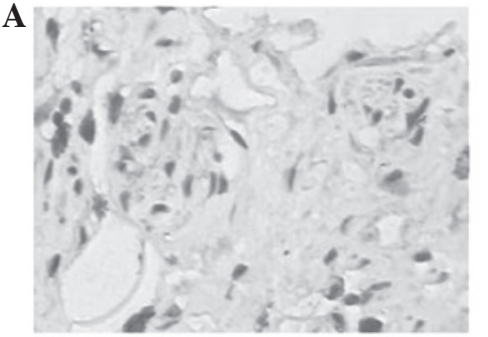

D

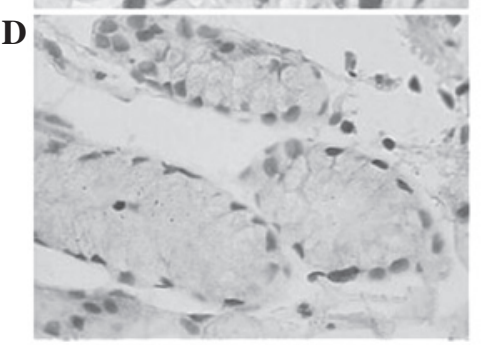

G

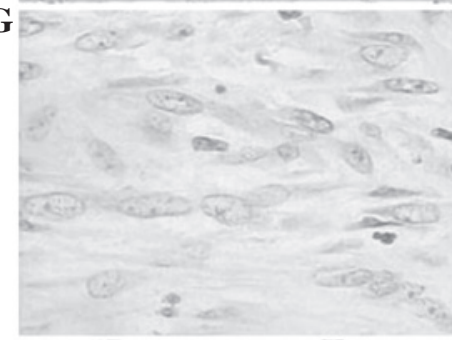

J

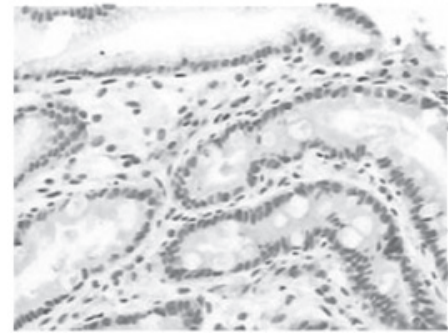

B

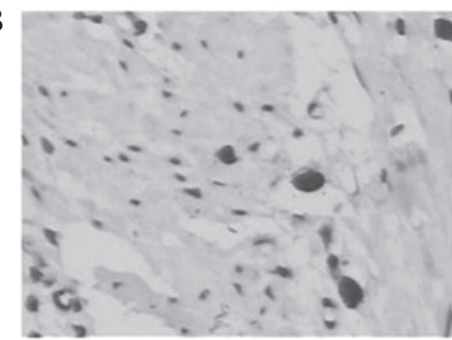

E

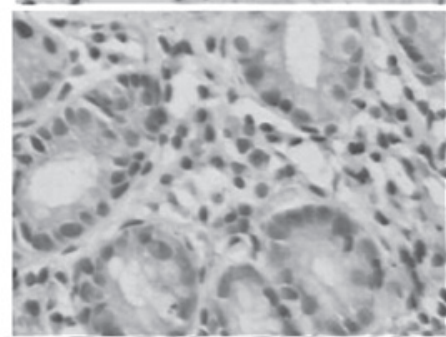

H

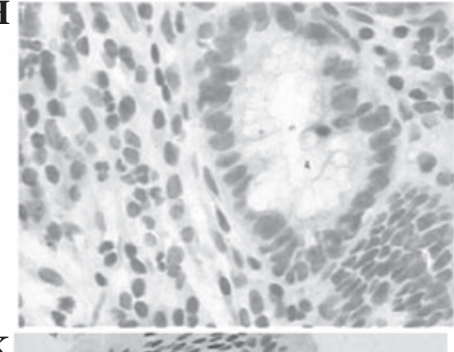

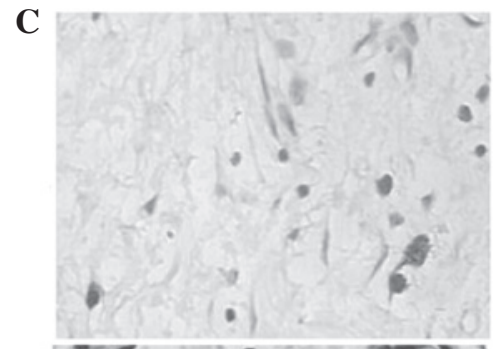

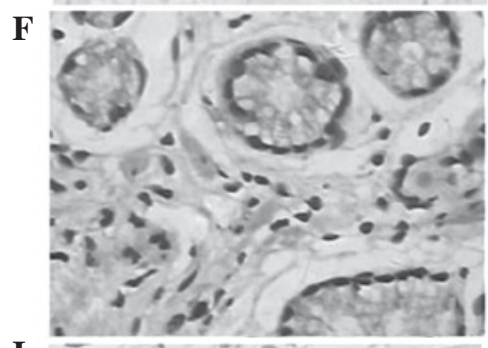

I

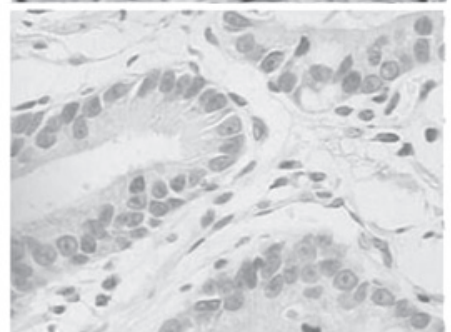

K
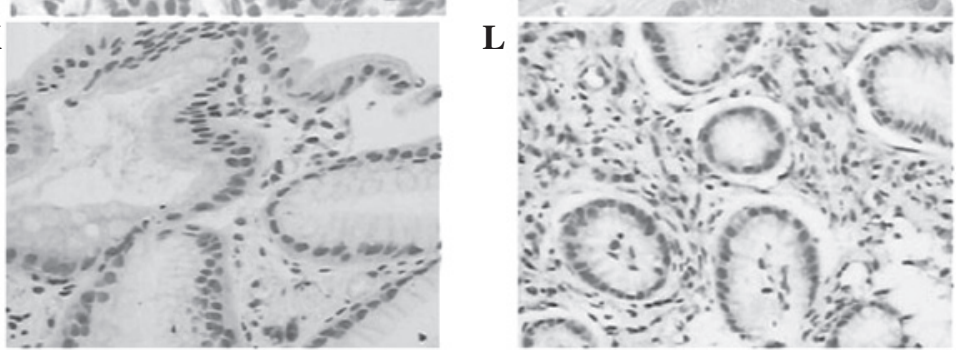

Figure 1. Expression of NICD and p21 proteins in gastric tissues, detected by immunohistochemistry. Expression of NICD protein in (A) poorly differentiated adenocarcinoma; (B) moderately differentiated adenocarcinoma; (C) well-differentiated adenocarcinoma; (D) precancerous gastric conditions, atrophic gastritis with intestinal metaplasia; (E) chronic superficial gastritis; and (F) normal gastric mucosa. Expression of p21 protein in (G) poorly differentiated adenocarcinoma; (H) moderately-differentiated adenocarcinoma,; (I) well-differentiated adenocarcinoma; (J) precancerous gastric conditions, atrophic gastritis with intestinal metaplasia; (K) chronic superficial gastritis; and (L) normal gastric mucosa (magnification, x400). NICD, Notch1 intracellular domain.

expressed in $67.9 \%(74 / 109), 36.8 \%(21 / 57), 30.0 \%(15 / 50)$ and $23.5 \%$ (4/17) of the gastric cancer, precancerous lesion, chronic superficial gastritis and normal gastric mucosa samples, respectively, suggesting that NICD expression was upregulated in the gastric cancer and premalignant lesions. The difference was statistically significant $\left(\chi^{2}, 30.57 ; \mathrm{P}<0.01\right)$. $\mathrm{NICD}^{+}$expression was significantly greater in the gastric cancer samples than in the precancerous lesion $\left(\chi^{2}, 14.74 ; \mathrm{P}<0.01\right)$, chronic superficial gastritis $\left(\chi^{2}, 19.97 ; \mathrm{P}<0.01\right)$ and normal gastric mucosa $\left(\chi^{2}, 12.27 ; \mathrm{P}<0.01\right)$ samples. However, there was no statistically significant difference in NICD expression between the precancerous lesion and chronic superficial gastritis $\left(\chi^{2}, 0.56\right.$; $\mathrm{P}>0.05)$ or normal gastric mucosa $\left(\chi^{2}, 1.04 ; \mathrm{P}>0.05\right)$ samples, or between the chronic superficial gastritis and normal gastric mucosa $\left(\chi^{2}, 0.26 ;\right.$ P $\left.>0.05\right)$ samples. Furthermore, p21 expression was also analyzed in these tissues. The p21 protein was located in the nuclei and was expressed in $38.5 \%(42 / 109)$, $75.4 \%$ (43/57), $82.0 \%(41 / 50)$ and $82.4 \%$ (14/17) of the gastric cancer, precancerous lesion, chronic superficial gastritis and normal gastric mucosa samples, respectively, suggesting that p21 protein was downregulated from normal mucosae through premalignant lesions to gastric cancer $\left(\chi^{2}, 40.24 ; \mathrm{P}<0.01\right)$. $\mathrm{p} 21^{+}$ expression was significantly lower in the gastric cancer than in precancerous lesion $\left(\chi^{2}, 20.40 ; \mathrm{P}<0.01\right)$, chronic superficial gastritis $\left(\chi^{2}, 25.96 ; \mathrm{P}<0.01\right)$ and normal gastric mucosa $\left(\chi^{2}\right.$, 11.44; $\mathrm{P}<0.01)$ samples. However, there was no significant difference in $\mathrm{p} 21$ expression between the precancerous lesion and chronic superficial gastritis samples $\left(\chi^{2}, 0.68 ; \mathrm{P}>0.05\right)$, between the precancerous lesion and normal gastric mucosa samples $\left(\chi^{2}, 0.35 ; \mathrm{P}>0.05\right)$ or between the chronic superficial gastritis and normal gastric mucosa samples $\left(\chi^{2}, 0.01 ; \mathrm{P}>0.05\right)$ (Table I; Fig. 1).

Association of NICD and 21 expression with clinicopathological features of gastric cancer patients. To assess the clinical significance of NICD and p21 expression, the expression levels of the proteins were analyzed against the clinicopathological features of the gastric cancer patients. The data revealed that NICD protein expression was significantly associated with a larger tumor size $\left(\chi^{2}, 5.40 ; \mathrm{P}<0.05\right)$, tumor dedifferentiation 
Table I. Differential expression of NICD and p21 proteins in gastric tissue specimens.

A, Positive rate of NICD and p21 proteins in differential specimens.

\begin{tabular}{|c|c|c|c|c|c|c|c|}
\hline Group & $\mathrm{n}$ & $\mathrm{NICD}^{+}, \mathrm{n}(\%)$ & $\chi^{2}$ & P-value & $\mathrm{p} 21^{+}, \mathrm{n}(\%)$ & $\chi^{2}$ & P-value \\
\hline Gastric cancer & 109 & $74(67.89)$ & 30.57 & $\mathrm{P}<0.01$ & $42(38.53)$ & 40.24 & $\mathrm{P}<0.01$ \\
\hline Precancerous lesions & 57 & $21(36.84)$ & & & $43(75.44)$ & & \\
\hline Chronic superficial gastritis & 50 & $15(30.00)$ & & & $41(82.00)$ & & \\
\hline Normal gastric mucosa & 17 & $4(23.53)$ & & & $14(82.35)$ & & \\
\hline
\end{tabular}

$\mathrm{B}$, Comparison between differential groups using $\chi^{2}$ test.

\begin{tabular}{|c|c|c|c|c|}
\hline Comparison & $\chi^{2}$ & P-value & $\chi^{2}$ & P-value \\
\hline Cancer vs. precancerous lesions & 14.47 & $<0.01$ & 20.40 & $<0.01$ \\
\hline Cancer vs. chronic superficial gastritis & 19.97 & $<0.01$ & 25.96 & $<0.01$ \\
\hline Cancer vs. normal gastric mucosa & 12.27 & $<0.01$ & 11.44 & $<0.01$ \\
\hline Precancerous lesions vs. chronic superficial gastritis & 0.56 & $>0.05$ & 0.68 & $>0.05$ \\
\hline Precancerous lesions vs. normal gastric mucosa & 1.04 & $>0.05$ & 0.35 & $>0.05$ \\
\hline Chronic superficial gastritis vs. normal gastric mucosa & 0.26 & $>0.05$ & 0.01 & $>0.05$ \\
\hline
\end{tabular}

NICD, Notch1 intracellular domain.

grade $\left(\chi^{2}, 16.85 ; \mathrm{P}<0.01\right)$, depth of tumor invasion $\left(\chi^{2}, 14.77\right.$ $\mathrm{P}<0.01)$, lymph node metastasis $\left(\chi^{2}, 4.82 ; \mathrm{P}<0.05\right)$, surface morphology $\left(\chi^{2}, 13.89 ; \mathrm{P}<0.01\right)$ and Lauren classification $\left(\chi^{2}\right.$, 4.60; $\mathrm{P}<0.05)$. By contrast, no association with age $\left(\chi^{2}, 2.45\right.$; $\mathrm{P}>0.05)$, gender $\left(\chi^{2}, 1.28 ; \mathrm{P}>0.05\right)$, tumor location $\left(\chi^{2}, 2.53\right.$; $\mathrm{P}>0.05)$, vascular invasion $\left(\chi^{2}, 1.13 ; \mathrm{P}>0.05\right)$ or distant metastasis $\left(\chi^{2}, 0.31 ; \mathrm{P}>0.05\right)$ was identified. Furthermore, a loss of p21 expression was closely associated with tumor dedifferentiation $\left(\chi^{2}, 15.45 ; \mathrm{P}<0.01\right)$, depth of tumor invasion $\left(\chi^{2}, 10.75\right.$; $\mathrm{P}<0.01)$, vascular invasion $\left(\chi^{2}, 5.12 ; \mathrm{P}<0.05\right)$, lymph node metastasis $\left(\chi^{2}, 5.21 ; \mathrm{P}<0.05\right)$, surface morphology $\left(\chi^{2}, 9.68\right.$; $\mathrm{P}<0.01)$ and Lauren classification $\left(\chi^{2}, 7.78 ; \mathrm{P}<0.01\right)$. There was also no association with age $\left(\chi^{2}, 2.20 ; \mathrm{P}>0.05\right)$, gender $\left(\chi^{2}, 0.00 ; \mathrm{P}>0.05\right)$, tumor location $\left(\chi^{2}, 0.80 ; \mathrm{P}>0.05\right)$, tumor size $\left(\chi^{2}, 0.23 ; \mathrm{P}>0.05\right)$ or distant metastasis $\left(\chi^{2}, 0.01 ; \mathrm{P}>0.05\right)$ (Table II).

Association between NICD and p21 expression in gastric cancer. NICD expression was compared with p21 expression in gastric cancer, and the results are provided in Table III. Spearman's rank correlation test showed that NICD protein expression was inversely associated with p21 protein expression.

Association of NICD and p21 expression with overall survival of gastric cancer patients. In the present study, gastric cancer patients were followed up for overall survival until April 1,2011. The overall survival was defined as the time from the surgery to April 1, 2011, provided that the patient survived until that date, or the date of mortality. The 109 gastric cancer patients were followed up for 5-40 months with a mean follow-up time of $21.09 \pm 6.82$ months, among which there were 55 patients who succumbed to the disease prior to the last follow-up. The
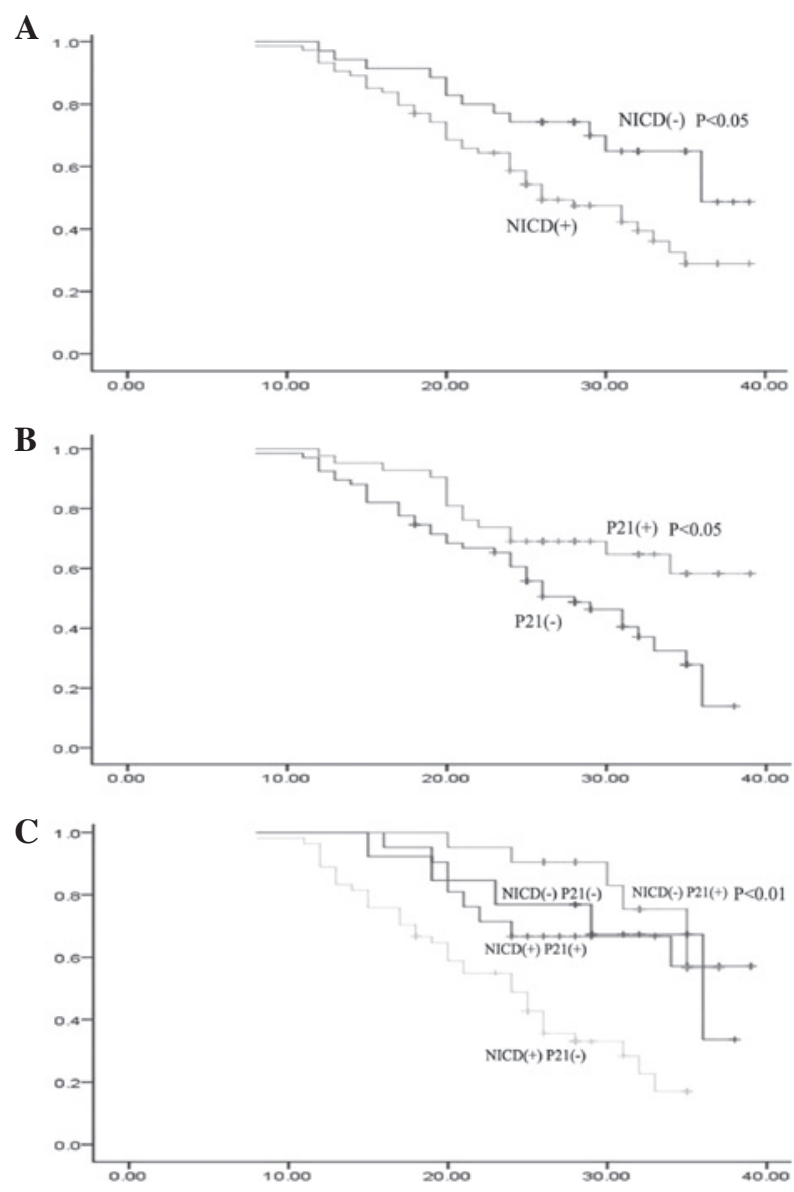

Figure 2. Association of NICD and p21 protein expression with the survival of gastric cancer patients. (A) Overall survival of gastric cancer patients with $\mathrm{NICD}^{+}$or NICD $\mathrm{N}^{-}$(B) Overall survival of gastric cancer patients with $\mathrm{p} 21^{+}$or $\mathrm{p} 21^{-}$. (C) Overall survival of gastric cancer patients with $\mathrm{NICD}^{-} / \mathrm{p} 21^{+}$, $\mathrm{NICD}^{-} / \mathrm{p} 21^{-}, \mathrm{NICD}^{+} / \mathrm{p} 21^{+}$or $\mathrm{NICD}^{+} / \mathrm{p} 21^{-}$. NICD, Notch1 intracellular domain. 
Table II. Association of NICD and p21 expression with the clinicopathological features of gastric cancer patients.

\begin{tabular}{|c|c|c|c|c|c|c|c|}
\hline Group & $\mathrm{n}$ & $\mathrm{NICD}^{+}, \mathrm{n}(\%)$ & $\chi^{2}$ & P-value & $\mathrm{p} 21^{+}, \mathrm{n}(\%)$ & $\chi^{2}$ & P-value \\
\hline \multicolumn{8}{|l|}{ Age (years) } \\
\hline$<60$ & 46 & $35(76.9)$ & \multirow[t]{2}{*}{2.45} & \multirow[t]{2}{*}{$>0.05$} & $14(30.4)$ & \multirow[t]{2}{*}{2.20} & \multirow[t]{2}{*}{$>0.05$} \\
\hline$\geq 60$ & 63 & $39(61.9)$ & & & $28(44.4)$ & & \\
\hline \multicolumn{8}{|l|}{ Gender } \\
\hline Male & 83 & $54(65.1)$ & \multirow[t]{2}{*}{1.28} & \multirow[t]{2}{*}{$>0.05$} & $32(38.6)$ & \multirow[t]{2}{*}{0.00} & \multirow[t]{2}{*}{$>0.05$} \\
\hline Female & 26 & $20(76.9)$ & & & $10(38.5)$ & & \\
\hline \multicolumn{8}{|l|}{ Location } \\
\hline Cardia and fundus & 18 & $12(66.7)$ & \multirow[t]{4}{*}{2.53} & \multirow[t]{4}{*}{$>0.05$} & 7 (38.9) & \multirow[t]{4}{*}{0.80} & \multirow[t]{4}{*}{$>0.05$} \\
\hline Gastric body & 39 & $29(74.4)$ & & & $14(35.9)$ & & \\
\hline Angular region & 12 & $6(50.0)$ & & & $6(50.0)$ & & \\
\hline Antrum and pylorus & 40 & $27(67.5)$ & & & $15(37.5)$ & & \\
\hline \multicolumn{8}{|l|}{ Tumor size $(\mathrm{cm})$} \\
\hline$<3$ & 42 & $23(54.8)$ & \multirow[t]{2}{*}{5.40} & \multirow[t]{2}{*}{$<0.05$} & $15(35.7)$ & \multirow[t]{2}{*}{0.23} & \multirow[t]{2}{*}{$>0.05$} \\
\hline$\geq 3$ & 67 & $51(76.1)$ & & & $27(40.3)$ & & \\
\hline \multicolumn{8}{|l|}{ Differentiation } \\
\hline Well and moderate & 47 & $22(46.8)$ & \multirow[t]{2}{*}{16.85} & \multirow[t]{2}{*}{$<0.01$} & $28(59.6)$ & \multirow[t]{2}{*}{15.45} & \multirow[t]{2}{*}{$<0.01$} \\
\hline Poor & 62 & $52(83.9)$ & & & $14(22.6)$ & & \\
\hline \multicolumn{8}{|l|}{ Depth of tumor invasion } \\
\hline $\mathrm{T} 1+\mathrm{T} 2$ & 30 & $20(66.7)$ & \multirow[t]{2}{*}{14.77} & $<0.01$ & $19(63.3)$ & 10.75 & $<0.01$ \\
\hline $\mathrm{T} 3+\mathrm{T} 4$ & 79 & $55(69.6)$ & & & $23(29.1)$ & & \\
\hline Vascular invasion & & & & & & & \\
\hline Positive & 64 & $46(71.9)$ & 1.13 & $>0.05$ & $19(29.7)$ & 5.12 & $<0.05$ \\
\hline Negative & 45 & $28(62.2)$ & & & $23(51.1)$ & & \\
\hline Lymph node metastasis & & & & & & & \\
\hline Positive & 69 & $52(75.4)$ & 4.82 & $<0.05$ & $21(30.4)$ & 5.21 & $<0.05$ \\
\hline Negative & 40 & $22(55.0)$ & & & $21(52.5)$ & & \\
\hline Distant metastasis & & & & & & & \\
\hline Positive & 10 & $6(60.0)$ & 0.31 & $>0.05$ & $4(40.0)$ & 0.01 & $>0.05$ \\
\hline Negative & 99 & $68(68.7)$ & & & $38(38.3)$ & & \\
\hline Surface morphology & & & & & & & \\
\hline Early gastric cancer & 11 & $2(18.2)$ & 13.89 & $<0.01$ & $9(81.8)$ & 9.68 & $<0.01$ \\
\hline Progressive gastric cancer & 98 & $72(73.5)$ & & & $33(33.7)$ & & \\
\hline Lauren Classification & & & & & & & \\
\hline Intestinal type & 65 & $39(60.0)$ & 4.60 & $<0.05$ & $32(49.2)$ & 7.78 & $<0.01$ \\
\hline Diffused type & 44 & 35 (79.6) & & & $10(22.7)$ & & \\
\hline
\end{tabular}

NICD, Notch1 intracellular domain.

two- and three-year survival rates of $\mathrm{NICD}^{+}(58.7$ and $28.9 \%$, respectively) gastric cancer patients were significantly lower than those that were NICD $^{-}\left(74.30\right.$ and $48.70 \%$, respectively; $\chi^{2}$, $6.01 ; \mathrm{P}<0.05$; Fig. 2A). The three-year survival rate of gastric cancer patients with $\mathrm{p} 21^{+}(58.3 \%)$ expression was significantly greater than that of $\mathrm{p} 21^{-}$patients $(13.90 \%)\left(\chi^{2}, 6.84 ; \mathrm{P}<0.05\right.$; Fig. 2B). The survival rates were determined using the expression data of NICD and $\mathrm{p} 21$, and the two- and three-year survival rates were 90.5 and $57.1 \%, 67.0$ and $33.7 \%, 66.7$ and $56.5 \%$ and 48.8 and $17.0 \%$ in $\mathrm{NICD}^{-} / \mathrm{p} 21^{+}, \mathrm{NICD}^{-} / \mathrm{p} 21^{-}, \mathrm{NICD}^{+} / \mathrm{p} 21^{+}$and $\mathrm{NICD}^{+} / \mathrm{p} 21^{-}$patients, respectively. Furthermore, the survival rate in $\mathrm{NICD}^{-} / \mathrm{p} 21^{+}$patients was significantly higher than that of $\mathrm{NICD}^{+} / \mathrm{p} 21^{-}$patients $\left(\chi^{2}, 15.57\right.$; $\mathrm{P}<0.01$; Fig. $\left.2 \mathrm{C}\right)$.

Univariate and multivariate analyses of prognostic factors for overall survival of gastric cancer patients. Univariate and multivariate analyses of prognostic factors were performed for overall survival of gastric cancer patients using the Cox proportional hazards regression model. Among the 11 factors that were analyzed (age, gender, tumor location, tumor size, tumor differentiation, depth of tumor invasion, vascular invasion, lymph node and distant metastasis, and NICD and p21 
Table III. Association of NICD and p21 protein expression.

\begin{tabular}{lccc}
\hline Group & $\mathrm{n}(\%)$ & $\chi^{2}$ & P-value \\
\hline $\mathrm{NICD}^{+} / \mathrm{p} 21^{+}$ & $20(18.35)$ & 7.40 & $\mathrm{P}<0.01$ \\
$\mathrm{NICD}^{-} / \mathrm{p} 21^{-}$ & $13(11.93)$ & & \\
$\mathrm{NICD}^{+} / \mathrm{p} 21^{-}$ & $54(49.54)$ & & \\
$\mathrm{NICD}^{-} / \mathrm{p} 21^{+}$ & $22(20.18)$ & & \\
\hline
\end{tabular}

NICD, Notch1 intracellular domain.

protein expression; Table IV), the univariate analysis showed that tumor differentiation, depth of tumor invasion, vascular invasion, lymph node metastasis, and $\mathrm{NICD}^{+}$and $\mathrm{p} 21^{+}$protein expression were eligible for the multivariate analysis (Table V). The multivariate analysis revealed that only $\mathrm{NICD}^{+}$or $\mathrm{p} 21^{+}$ protein expression, depth of tumor invasion and lymph node metastasis had statistical significance. $\mathrm{NICD}^{+}$or $\mathrm{p}^{-} 1^{-}$protein expression, depth of tumor invasion and lymph node metastasis were independent prognostic factors of gastric cancer (Tables III and IV).

\section{Discussion}

The present study identified differential expression of the NICD and p21 proteins in gastric cancer tissue specimens compared with in normal mucosa, gastritis and precancerous lesion samples. NICD was upregulated, but p21 protein was downregulated, in the gastric cancer tissues, and the two proteins were shown to be inversely associated. Furthermore, increased NICD expression, but a loss of p21 expression, was closely associated with tumor dedifferentiation, depth of tumor invasion, lymph node metastasis, surface morphology and Lauren classification in gastric cancer. The overall survival rate of gastric cancer patients was greater in those with $\mathrm{NICD}^{-}$as opposed to $\mathrm{NICD}^{+}$tumors, and in $\mathrm{p}^{2} 1^{+}$rather than in $\mathrm{p} 21^{-}$tumors. The altered expression of these two proteins was also associated with the overall survival of the patients. The COX-regression multivariate analysis showed that $\mathrm{NICD}^{+}$, $\mathrm{p} 21^{-}$, depth of tumor invasion and lymph node metastasis were all independent prognostic factors for gastric cancer patients. Future studies will further evaluate these two proteins as novel prognostic markers for gastric cancer patients.

Using a pancreatic cancer mouse model (Rosa ${ }^{26 \mathrm{NICD}}$ ), De La et al (18) demonstrated that the abnormal activation of Notch1 signaling leads to excessive epithelial cell proliferation, decreased apoptosis and malignant transformation of the epithelial phenotype, consequently resulting in the development of pancreatic intraepithelial neoplasms and cancer in the mice. The present study showed that NICD protein expression was significantly greater in poorly-differentiated gastric cancer compared with that in well- and moderately differentiated tumors. Furthermore, NICD expression was closely associated with tumor size, depth of tumor invasion, lymph node metastasis, surface morphology and Lauren classification of tumors. These ex vivo data are consistent with the previously mentioned data on pancreatic cancer in mice.
Similarly, Fre et al (19) identified that the overexpression of NICD through transgenic technology significantly inhibited the differentiation of crypt progenitor cells in the mouse intestine. In glioma, Fan et al (20) demonstrated that the inhibition of Notch1 signaling activation reduced the proportion of glioma stem cells, inhibited tumor cell colony formation and increased tumor cell differentiation and apoptosis. In gastric cancer, Yeh et al (21) revealed that the overexpression of the NICD protein in gastric adenocarcinoma SC-M1 cells using gene transfection techniques resulted in a marked increase in tumor cell colony formation, migration, invasion, xenograft formation and growth. Recently, Notch1 protein expression has been shown to regulate stem cells and cancer stem cells. The constitutive activation of Notch1 signaling in Sertoli cells has been shown to cause gonocytes to exit from quiescence (22). Notch overexpression has been demonstrated to preserve stem cell characteristics and confer stem cell characteristics upon a subset of progenitor cells (23). Furthermore, Notch1 is able to promote $\mathrm{T}$ cell leukemia-initiating activity by RUNX-mediated regulation of PKC- $\theta$ and reactive oxygen species (24). However, Notch1 inhibition in vivo results in mammary tumor regression and reduces mammary tumor sphere-forming activity in vitro (25). The inhibition of the Notch1 pathway has been shown to allow glioblastoma cells to overcome apoptosis resistance and become sensitized to apoptosis that is induced by ionizing radiation, the death ligand tumor necrosis factor-related apoptosis-inducing ligand or the Bcl-2/Bcl-XL inhibitor ABT-737 (26). In conclusion, Notch1 may be a novel target for gastric cancer therapy.

Furthermore, p21 expression has been shown to be reduced or lost in a variety of cancer types $(27,28,29)$. A possible explanation is that $\mathrm{p} 21$ functions as a regulator of cell cycle progression at $\mathrm{S}$ phase, therefore preventing cell proliferation. In addition, p21 expression is controlled by the tumor suppressor protein, $\mathrm{p} 53$, which is frequently mutated in a number of human cancers, thus significantly contributing to a loss of p21 expression in various cancer tissues. In the present study, a gradual reduction of p21 protein expression from normal gastric mucosa, chronic superficial gastritis and precancerous gastric lesions to gastric cancer was observed. The loss of p21 expression was associated with tumor dedifferentiation, depth of tumor invasion, vascular invasion, lymph node metastasis, surface morphology and Lauren classification of gastric cancer. These data suggest that p21 plays a suppressor role in the development and progression of gastric cancer, the expression of which may aid in controlling a variety of malignant behaviors of gastric cancer. Furthermore, the effect of activated Notch1 signaling (NICD) on the regulation of p21 expression may differ in various tumor cell types. However, the majority of studies support that Notch1 expression inhibits p21 expression and activation or vice versa (30). p21WAF1/Cip1 is a negative transcriptional regulator of Wnt4 expression downstream of Notch1 activation (31). The adult stem cell marker Musashi-1 modulates endometrial carcinoma cell cycle progression and apoptosis via Notch1 and p21 (32). Silencing of SKP2 by RNA interference in G1 stabilizes p27 and $\mathrm{p} 21$ but abolishes the Notch1 effect on G1-S progression (33). Kim et al (12) also observed that the overexpression of NICD inhibits 53 phosphorylation and the expression of the p53 target gene, p21, therefore inhibiting ultraviolet-induced 
Table IV. Univariate analysis of prognostic factors for the overall survival of gastric cancer patients.

\begin{tabular}{lrrrcccc}
\hline & & & & & & \multicolumn{2}{c}{$95 \%$ confidence bounds } \\
\cline { 6 - 8 } Variable & $\beta$ & SE & Wald & P-value & OR & Lower limit & Upper limit \\
\hline Age (years) & -0.15 & 0.28 & 0.29 & 0.59 & 0.86 & 0.50 & 1.47 \\
Gender (n) & 0.12 & 0.32 & 0.13 & 0.71 & 1.12 & 0.60 & 2.09 \\
Tumor size (cm) & -0.34 & 0.30 & 1.29 & 0.26 & 0.71 & 0.40 & 1.28 \\
Tumor location (n) & -0.01 & 0.13 & 0.00 & 0.96 & 0.99 & 0.77 & 1.29 \\
Differentiation (n) & 0.60 & 0.29 & 4.36 & 0.04 & 1.83 & 1.04 & 3.22 \\
Depth of tumor invasion (n) & 1.34 & 0.29 & 21.34 & 0.00 & 3.80 & 2.16 & 6.71 \\
Vascular invasion (n) & 0.71 & 0.30 & 5.71 & 0.02 & 2.04 & 1.14 & 3.65 \\
Lymph node metastasis (n) & 1.04 & 0.33 & 9.74 & 0.00 & 2.82 & 1.47 & 5.41 \\
Distant metastasis (n) & 0.45 & 0.41 & 1.22 & 0.27 & 1.57 & 0.71 & 3.47 \\
NICD protein (n) & 1.19 & 0.35 & 11.34 & 0.00 & 3.27 & 1.64 & 6.53 \\
p21 protein (n) & -1.14 & 0.32 & 12.58 & 0.00 & 0.32 & 0.17 & 0.60 \\
\hline
\end{tabular}

$\beta$, coefficient of regression; SE, standard error of the mean; OR, odds ratio; NICD, Notch1 intracellular domain.

Table V. Multivariate analysis of prognostic factors for the overall survival of gastric cancer patients.

\begin{tabular}{lccccccc}
\hline & & & & & & \multicolumn{2}{c}{$95 \%$ confidence bounds } \\
\cline { 6 - 8 } Variable & $\beta$ & SE & Wald & P-value & OR & Lower limit & Upper limit \\
\hline Tumor differentiation & 0.10 & 0.31 & 0.11 & 0.74 & 1.11 & 0.60 & 2.03 \\
Depth of tumor invasion & 1.10 & 0.30 & 14.29 & 0.00 & 3.00 & 1.70 & 5.31 \\
Vascular invasion & -0.10 & 0.32 & 0.10 & 0.76 & 0.91 & 0.49 & 1.69 \\
Lymph node metastasis & 1.66 & 0.41 & 16.12 & 0.00 & 5.23 & 2.33 & 11.73 \\
NICD protein & 0.83 & 0.39 & 4.39 & 0.04 & 2.28 & 1.06 & 4.94 \\
p21 protein & -0.70 & 0.34 & 4.37 & 0.04 & 0.50 & 0.26 & 0.96 \\
\hline
\end{tabular}

$\beta$, coefficient of regression; SE, standard error of the mean; OR, odds ratio; NICD, Notch1 intracellular domain.

apoptosis. These data indicate that Notch1 may function by regulating p21 expression. The present study supports this notion. However, further studies are required to clarify Notch regulation of p21 expression in gastric cancer cells.

The present study demonstrated that a combination of aberrant expression of NICD and p21 proteins was able to predict overall survival of gastric cancer patients, which is more efficient than that of an individual protein. The present data are consistent with the data reported by Li et al (34). Thus, the NICD and p21 proteins may be useful as prognostic indicators for gastric cancer. However, the present data showed that the expression of the two proteins was significantly altered in gastric cancer tissues, although they were not significantly altered in the early stages of malignancy, including precancerous lesions versus chronic superficial gastritis or normal gastric mucosae, or chronic superficial gastritis versus normal gastric mucosae, indicating that they may be late events during stomach carcinogenesis. Thus, they are not useful for early detection or as tumorigenesis markers of gastric cancer.

\section{Acknowledgements}

This study was supported by a grant from the Natural Science Foundation of Zhejiang Province (grant no. Y2101458) and the Innovation Technology Project for High-Level Personnel of Wenzhou City (201011). The authors would like to thank the Pathology Department of The First Hospital Affiliated with Wenzhou Medical College for the analysis of the pathological data.

\section{References}

1. Jemal A, Bray F, Center MM, Ferlay J, Ward E and Forman D: Global cancer statistics. CA Cancer J Clin 61: 69-90, 2011.

2. Lin Y, Ueda J, Kikuchi S, et al: Comparative epidemiology of gastric cancer between Japan and China. World J Gastroenterol 17: 4421-4428, 2011.

3. Artavanis-Tsakonas S, Rand MD and Lake RJ: Notch signaling: cell fate control and signal integration in development. Science 284: 770-776, 1999.

4. Koch U and Radtke F: Notch and cancer: a double-edged sword. Cell Mol Life Sci 64: 2746-2762, 2007. 
5. Stanley P: Regulation of Notch signaling by glycosylation. Curr Opin Struc Biol 17: 530-535, 2007.

6. Katoh $\mathrm{M}$ and Katoh $\mathrm{M}$ : Notch signaling in gastrointestinal tract (review). Int J Oncol 30: 247-251, 2007.

7. Sriuranpong V, Borges MW, Ravi RK, et al: Notch signaling induces cell cycle arrest in small cell lung cancer cells. Cancer Res 61: 3200-3205, 2001.

8. Duan L, Yao J, Wu X and Fan M: Growth suppression induced by Notch1 activation involves Wnt-beta-catenin down-regulation in human tongue carcinoma cells. Biol Cell 98: 479-490, 2006.

9. Kunnimalaiyaan M, Vaccaro AM, Ndiaye MA and Chen $\mathrm{H}$ : Overexpression of the NOTCH1 intracellular domain inhibits cell proliferation and alters the neuroendocrine phenotype of medullary thyroid cancer cells. J Biol Chem 281: 39819-39830, 2006.

10. Cayo MA, Cayo AK, Jarjour SM and Chen H: Sodium butyrate activates Notch1 signaling, reduces tumor markers, and induces cell cycle arrest and apoptosis in pheochromocytoma. Am J Transl Res 1: 178-183, 2009.

11. Greblatt DY, Vaccaro AM, Jaskula-Sztul R, et al: Valproic acid activates notch-1 signaling and regulates the neuroendocrine phenotype in carcinoid cancer cells. Oncologist 12: 942-951, 2007.

12. Kim SB, Chae GW, Lee J, et al: Activated Notch1 interacts with p53 to inhibit its phosphorylation and transactivation. Cell Death Differ 14: 982-991, 2007.

13. Ning L, Wentworth L, Chen H and Weber SM: Down-regulation of Notch1 signaling inhibits tumor growth in human hepatocellular carcinoma. Am J Transl Res 1: 358-366, 2009.

14. Tanaka M, Setoguchi T, Hirotsu M, et al: Inhibition of Notch pathway prevents osteosarcoma growth by cell cycle regulation. Br J Cancer 100: 1957-1965, 2009.

15. Guo D, Ye J, Dai J, et al: Notch-1 regulates Akt signaling pathway and the expression of cell cycle regulatory proteins cyclin D1, CDK2 and p21 in T-ALL cell lines. Leuk Res 33: 678-685, 2009.

16. Massi D, Tarantini F, Franchi A, et al: Evidence for differential expression of Notch receptors and their ligands in melanocytic nevi and cutaneous malignant melanoma. Mod Pathol 19: 246-254, 2006

17. Tarakji B and Nassani MZ: Immunohistochemical expression of p21 in normal tissues of salivary gland, pleomorphic adenoma and carcinoma ex pleomorphic adenoma-(undifferentiated and adenocarcinoma types). Med Oral Patol Oral Cir Bucal 15: e697-e703, 2010.

18. De La O JP, Emerson LL, Goodman JL, et al: Notch and Kras reprogram pancreatic acinar cells to ductal intraepithelial neoplasia. Proc Natl Acad Sci USA 105: 18907-18912, 2008.

19. Fre S, Huyghe M, Mourikis P, et al: Notch signals control the fate of immature progenitor cells in the intestine. Nature 435: 964-968, 2005
20. Fan X, Matsui W, Khaki L, et al: Notch pathway inhibition depletes stem-like cells and blocks engraftment in embryonal brain tumors. Cancer Res 66: 7445-7452, 2006.

21. Yeh TS, Wu CW, Hsu KW, et al: The activated Notch1 signal pathway is associated with gastric cancer progression through cyclooxygenase-2. Cancer Res 69: 5039-5048, 2009.

22. Garcia TX, Defalco T, Capel B and Hofmann MC: Constitutive activation of NOTCH1 signaling in Sertoli cells causes gonocyte exit from quiescence. Dev Biol 377: 188-201, 2013.

23. Piccin D, Yu F and Morshead C: Notch signaling imparts and preserves neural stem characteristics in the adult brain. Stem Cells Dev 22: 1541-1550, 2013.

24. Giambra V, Jenkins CR, Wang H, et al: NOTCH1 promotes T cell leukemia-initiating activity by RUNX-mediated regulation of PKC- $\theta$ and reactive oxygen species. Nat Med 18: 1693-1698, 2012.

25. Simmons MJ, Serra R, Hermance N and Kelliher MA: NOTCH1 inhibition in vivo results in mammary tumor regression and reduced mammary tumorsphere-forming activity in vitro. Breast Cancer Res 14: R126, 2012.

26. Fassl A, Tagscherer KE, Richter J, et al: Notch1 signaling promotes survival of glioblastoma cells via EGFR-mediated induction of anti-apoptotic Mcl-1. Oncogene 31: 4698-4708, 2012.

27. Skirnisdottir I and Seidal T: Association of p21,p21 p27 and p21 p53 status to histological subtypes and prognosis in low-stage epithelial ovarian cancer. Cancer Genomics Proteomics 10: 27-34, 2013.

28. Place RF, Wang J, Noonan EJ, et al: Formulation of small activating RNA into lipidoid nanoparticles inhibits xenograft prostate tumor growth by inducing p 21 expression. Mol Ther Nucleic Acids 1: e15, 2012.

29. Jee H, Lee SH, Park JW, et al: Connexin32 inhibits gastric carcinogenesis through cell cycle arrest and altered expression of p21Cip1 and p27Kip1. BMB Rep 46: 25-30, 2013.

30. Rowland BD and Peeper DS: KLF4, p21 and context-dependent opposing forces in cancer. Nat Rev Cancer 6: 11-23, 2006.

31. Devgan V, Mammucari C, Millar SE, et al: p21WAF1/Cip1 is a negative transcriptional regulator of Wnt4 expression downstream of Notch1 activation. Genes Dev 19: 1485-1495, 2005.

32. Götte M, Greve B, Kelsch R, et al: The adult stem cell marker Musashi-1 modulates endometrial carcinoma cell cycle progression and apoptosis via Notch-1 and p21WAF1/CIP1. Int J Cancer 129: 2042-2049, 2011.

33. Sarmento LM, Huang H, Limon A, et al: Notch1 modulates timing of G1-S progression by inducing SKP2 transcription and p27 Kip1 degradation. J Exp Med 202: 157-168, 2005.

34. Li DW, Wu Q, Peng ZH, et al: Expression and significance of Notch1 and PTEN in gastric cancer. Ai Zheng 26: 1183-1187, 2007 (In Chinese) 